\title{
DIAGNÓSTICO QUALI-QUANTITATIVO DA ARBORIZAÇÃO VIÁRIA DE BONITO, MATO GROSSO DO SUL
}

\author{
Kendra Zamproni ${ }^{1 *}$, Daniela Biondi ${ }^{1}$, Tamara Ribeiro Botelho de Carvalho Maria ${ }^{2}$, Fernando Almeida Louveira ${ }^{3}$ \\ ${ }^{1}$ Universidade Federal do Paraná, Departamento de Ciências Florestais, Curitiba, Paraná, Brasil - kendra.zam@gmail.com*; \\ dbiondi@ufpr.br \\ ${ }^{2}$ Universidade Federal do Paraná, Programa de Pós-graduação em Engenharia Florestal, Curitiba, Paraná, Brasil - \\ trbotelhomaria@gmail.com \\ ${ }^{3}$ Universidade Federal de Grande Dourados, Curso de Gestão Ambiental, Dourados, Mato Grosso do Sul, Brasil - \\ fernando-f12@hotmail.com
}

Recebido para publicação: 06/05/2016 - Aceito para publicação: 23/01/2018

\begin{abstract}
Resumo
O diagnóstico da arborização viária é fundamental para o planejamento e manutenção desse patrimônio de modo a maximizar os benefícios proporcionados pelas árvores nas cidades. O objetivo desta pesquisa foi realizar o diagnóstico quali-quantitativo da arborização viária do município de Bonito (MS). Para tanto, foram contabilizados todos os indivíduos da área pavimentada do município. Para avaliação qualitativa, realizou-se um inventário por amostragem aleatória com parcelas lineares de $400 \mathrm{~m}$ de comprimento. Foram avaliados: espécie; altura total; altura de bifurcação; CAP; diâmetro de copa; condição fitossanitária; necessidade de tratamento; e condição de raiz. Foram encontrados 6.524 indivíduos na área pavimentada de Bonito (MS). Verificou-se o predomínio da espécie Licania tomentosa (Benth.) Fritsch. (oiti), que compunha 63,27\% da arborização viária. A distribuição em classes de área de copa demonstrou alta proporção de indivíduos com área de copa pequena, provenientes de arborização jovem e podas inadequadas. Cerca de $80 \%$ dos indivíduos tinham altura da primeira bifurcação inferior a 1,8 m. Mais de $50 \%$ das árvores foram classificadas como regulares, com condição física e vigor medianos. A adoção de medidas de manejo e manutenção adequadas para a aborização viária proporcionarão um ambiente de melhor qualidade e valorizarão ainda mais o município.

Palavras-chave: Inventário, árvores de rua, planejamento urbano.
\end{abstract}

\begin{abstract}
Quali-quantitative diagnosis of street trees of Bonito $(M S)$. The diagnosis through street trees assessment is fundamental for the planning and maintenance of this asset in order to maximize the benefits provided by trees in the cities. This research aimed to carry out a quali-quantitative diagnostic of street afforestation of the city of Bonito (state of Mato Grosso do Sul, Brazil). For that, all trees from the paved area of the municipality were counted. For the qualitative analysis, a random sampling inventory was carried out in linear parcels of $400 \mathrm{~m}$. The variables obtained were: species; total height; bifurcation height; $\mathrm{CBH}$; canopy diameter; phytosanitary condition; need of treatment; and root condition. There were 6,524 individuals counted in the paved area of Bonito. The predominance of Licania tomentosa (Benth.) Fritsch. (oiti) was verified; it composed $63.27 \%$ of the street afforestation. The distribution into canopy classes demonstrated a high proportion of individuals with small canopy from the young afforestation and poorly executed pruning. About $80 \%$ of the trees had first bifurcation height inferior to $1.8 \mathrm{~m}$. More than $50 \%$ of the trees were classified as regulars, with medium physical condition and vigor. Adoption of adequate management and maintenance actions for street afforestation will provide a better-quality environment and further increase the value of the city.

Keywords: Inventory, street trees, urban planning.
\end{abstract}

\section{INTRODUÇÃO}

Atualmente, como já é notório, a maior parte da população mundial reside nas cidades. Estas possuem algumas características em comum, independentemente de sua localização ao redor do planeta, tais quais: ruas e avenidas, edificações (comerciais, residenciais, industriais, entre outras), espaços de lazer e infraestrutura (calçada, rede aérea, iluminação, sinalização). Todos esses elementos compõem uma paisagem artificial, isto é, com características divergentes do natural, o que a evidencia como um ambiente ecologicamente desequilibrado.

Esse cenário criou desafios para a gestão pública uma vez que se demanda que providenciem o bem-estar ecológico e social para os habitantes (BAUR et al., 2016). A floresta urbana, de modo especial a arborização viária, se insere como elemento estruturador do espaço nesse contexto, pois proporciona inúmeros benefícios ecológicos, estéticos, sociais e econômicos, que auxiliam na qualidade ambiental e promovem maior bem-estar humano.

FLORESTA, Curitiba, PR, v. 48, n. 2, p. 235-244, abr/jun 2018

Zamproni. K. et.al.

ISSN eletrônico 1982-4688

DOI: $10.5380 /$ rf.v48 i2.55531 
Devido aos inúmeros benefícios advindos das características naturais das árvores, a arborização de vias públicas tem ganhado espaço nas deliberações dos municípios na busca de melhor qualidade de vida para seus cidadãos. Porém, para que esse elemento se desenvolva de forma saudável, com o mínimo de manutenção necessária, e cumpra suas funcionalidades no meio urbano, o planejamento é essencial (KORDY et al., 2016).

Segundo Oliveira et al. (2017), é indispensável que haja planejamento adequado da arborização já que sua ausência ou inadequação podem ocasionar diversos problemas. Conforme Ribeiro (2009), o planejamento está relacionado aos danos ocasionados pelas árvores aos equipamentos urbanos, como fiações aéreas, encanamentos, calhas, calçadas, muros, postes de iluminação, entre outros, e aos danos às árvores, como as podas inadequadas, vários problemas fitossanitários e injúrias físicas. É importante ressaltar que as árvores representam custos para a municipalidade. Deve-se, então, minimizar os danos para maximizar os benefícios, de modo a valorizar os investimentos nesse patrimônio público.

Dessa maneira, faz-se necessário conhecer a arborização viária de um município para que se possa embasar ações de manejo e manutenção necessárias para a conservação das árvores. Esse conhecimento decorre de um diagnóstico, dependente da realização de um inventário florestal urbano. As informações obtidas com os inventários referem-se a localização, espécies, porte e condição das árvores (NOWAK, 2008). Por meio do inventário, é possível identificar as necessidades de manejo, localizar riscos relacionados a árvores que necessitem de reparos ou remoção, verificar as características das ruas e elementos urbanos e indicar novos pontos para plantio (BENATTI et al., 2012).

O município de Bonito, localizado no estado do Mato Grosso do Sul, é internacionalmente conhecido por suas belezas naturais, que atraem turistas de todos os lugares do mundo. No que se refere à área urbana, no entanto, até o momento da presente pesquisa, não havia informações sobre as árvores que compõem a arborização viária e que podem representar mais uma fonte de atração turística. Assim, o objetivo deste trabalho foi realizar o diagnóstico quali-quantitativo das árvores que compõem a arborização viária do município de Bonito.

\section{MATERIAL E MÉTODOS}

O município de Bonito localiza-se no sudoeste do estado do Mato Grosso do Sul, na região centro-oeste do Brasil (Figura 1), e faz parte da unidade geomorfológica denominada Serra da Bodoquena. O núcleo urbano do município, coordenadas $21^{\circ} 07^{\prime} 16^{\prime \prime} \mathrm{S}$ e $56^{\circ} 28^{\prime} 55^{\prime} \mathrm{O}$, está a $250 \mathrm{~km}$ da capital do estado, cidade de Campo Grande (FEHLAUER et al., 2010).

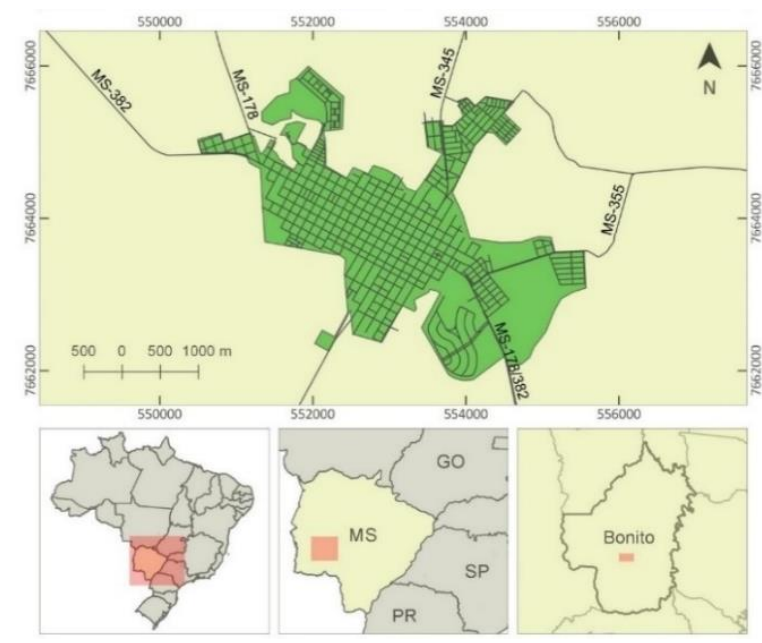

Figura 1. Localização geográfica de Bonito (MS), com destaque para a área urbana do município.

Figure 1. Geographic location of Bonito (state of Mato Grosso do Sul, Brazil), urban area highlighted.

O clima da região é o Aw (tropical úmido), segundo a classificação de Köppen, caracterizado por estação seca acentuada entre os meses de abril e setembro, com precipitações concentradas entre novembro e janeiro. A temperatura média anual é de $23,9^{\circ} \mathrm{C}$, e a precipitação varia entre 1200 e $1500 \mathrm{~mm}$ ao ano (SILVA et al., 2013). De acordo com o IBGE (2016), o município de Bonito possui área de 4.934,414 km², sendo $3,483 \mathrm{~km}^{2}$ de área urbana, e uma população estimada de 21.267 habitantes. Mais de 16 mil pessoas (82,5\%) vivem na área urbana, enquanto o restante reside na área rural. Entre os anos de 2000 e 2010, houve um aumento de $6 \%$ da população da área urbana em relação à área rural (IBGE, 2010). 
Para a realização do inventário, a área urbanizada do município foi dividida em área pavimentada e área não pavimentada. Essa distinção foi feita para que o inventário quali-quantitativo contemplasse a área da cidade com o mínimo de infraestrutura urbana necessária (arruamento pavimentado e passeio para pedestres com calçamento). Para tanto, utilizou-se um mapa geral do arruamento do município, cedido pela Fundação Neotrópica do Brasil.

O inventário quantitativo foi do tipo censo, sendo percorridas, de carro, todas as ruas da cidade inseridas na área pavimentada previamente delimitada para contabilizar todos os indivíduos arbóreos e não arbóreos presentes na calçada. Já o inventário qualitativo foi realizado por amostragem aleatória, dentro da área estratificada, com parcelas lineares de 400 metros de comprimento, considerando um total de 126 trechos lineares devidamente traçados e enumerados no mapa de arruamento do município.

A intensidade amostral foi calculada ao nível de $95 \%$ de confiança para um erro de $10 \%$, por meio da equação para população finita:

$$
\begin{aligned}
& n=\frac{s^{2} t^{2}}{E^{2}+\left(\frac{s^{2} t^{2}}{N}\right)} \\
& E^{2}=(L E * \bar{X})
\end{aligned}
$$

Em que: $\mathrm{n}=$ tamanho da amostra; $\mathrm{N}=$ tamanho da população; $\mathrm{t}=$ valor tabelado de $\mathrm{t} ; \mathrm{s}^{2}=$ variância da variável de interesse analisada; $\mathrm{E}^{2}=$ erro amostral admitido; $\mathrm{LE}=$ limite máximo do erro amostral admitido; $\bar{X}=$ média estimada.

Para o cálculo da variância, utilizou-se o "número de árvores por metro de calçada" como variável, o que permitiu uma melhor homogeneização da variância.

As coletas de dados ocorreram nos meses de junho e julho de 2015 e as seguintes variáveis em campo foram obtidas: identificação da espécie; altura total (m); altura de bifurcação (m); circunferência a altura do peito (CAP) (cm); diâmetro de copa (m); condição física e fitossanitária (boa, satisfatória, ruim, muito ruim, morta); necessidade de tratamento; e condição da raiz (profunda, pouco superficial, superficial). Os dados obtidos com as medições foram transferidos para planilhas no Microsoft Office Excel 2013 e, posteriormente, foram processados e analisados em forma de gráficos e tabelas.

\section{RESULTADOS}

O inventário quantitativo indicou que Bonito possui 6.524 indivíduos que compõem a arborização viária da área pavimentada do município. Para o inventário qualitativo, foram caracterizadas 17 amostras lineares de 400 metros de comprimento. Nessas amostras, foram encontrados 947 indivíduos arbóreos e não arbóreos, distribuídos em 61 espécies, pertencentes a 23 famílias botânicas. Somente os indivíduos de porte arbóreo foram inventariados qualitativamente, somando 931 exemplares. Sua relação em espécie, origem e respectivas frequências absoluta e relativa em ordem decrescente é apresentada na Tabela 1. Verifica-se o predomínio da espécie Licania tomentosa (Benth.) Fritsch, popularmente conhecida como oiti, com 589 indivíduos, que representam 63,27\% da arborização viária de Bonito.

Tabela 1. Relação de indivíduos de porte arbóreo, origem, frequência absoluta (FA) e frequência relativa (FR) na arborização viária de Bonito (MS).

Table 1. Relation of tree size individuals, origin, absolute frequency (FA) and relative frequency (FR) of street trees from Bonito (state of Mato Grosso do Sul, Brazil).

\begin{tabular}{llllc}
\hline Nome Científico & Nome Popular & Origem & FA & FR $(\%)$ \\
\hline Licania tomentosa & Oiti & Nativa & 589 & 63,27 \\
Caesalpinia pluviosa & Sibipiruna & Nativa & 38 & 4,08 \\
Não identificado & Ipê & Nativa & 27 & 2,90 \\
Bauhinia sp. & Pata-de-vaca & Exótica & 24 & 2,58 \\
Pachira aquatica & Embiratanha & Nativa & 23 & 2,47 \\
Murraya exotica & Murta & Exótica & 21 & 2,26 \\
Tabebuia roseoalba & Ipê-branco & Nativa & 19 & 2,04 \\
Mangifera indica & Mangueira & Exótica & 16 & 1,72 \\
Tabebuia avellanedae & Ipê-rosa & Nativa & 14 & 1,50 \\
Lagerstroemia indica & Extremosa & Exótica & 13 & 1,40 \\
Schinus molle & Aroeira-salsa & Nativa & 8 & 0,86 \\
\hline
\end{tabular}

FLORESTA, Curitiba, PR, v. 48, n. 2, p. 235-244, abr/jun 2018

Zamproni. K. et.al.

ISSN eletrônico 1982-4688

DOI: $10.5380 /$ rf.v48 i 2.55531 


\begin{tabular}{|c|c|c|c|c|}
\hline Plumeria rubra & Jasmim-manga & Exótica & 7 & 0,75 \\
\hline Malpighia emarginata & Acerola & Exótica & 7 & 0,75 \\
\hline Ficus sp. & Ficus & Exótica & 7 & 0,75 \\
\hline Cocus nucifera & Coqueiro-da-Bahia & Nativa & 6 & 0,64 \\
\hline Syagrus oleracea & Guariroba & Nativa & 6 & 0,64 \\
\hline Syzygium cumini & Jamelão & Exótica & 6 & 0,64 \\
\hline Delonix regia & Flamboyant & Exótica & 5 & 0,54 \\
\hline Psidium guajava & Goiabeira & Nativa & 5 & 0,54 \\
\hline Terminalia catappa & Sombrero & Exótica & 4 & 0,43 \\
\hline Handroanthus ochraceus & Ipê-amarelo & Nativa & 4 & 0,43 \\
\hline Erythrina indica var. picta & Brasileirinho & Exótica & 4 & 0,43 \\
\hline Cassia fistula & Chuva-de-ouro & Exótica & 4 & 0,43 \\
\hline Melia azedarach & Cinamomo & Exótica & 4 & 0,43 \\
\hline Citrus sp. & Limoeiro & Exótica & 4 & 0,43 \\
\hline Melicoccus lepidopetalus & Água-pomba & Nativa & 4 & 0,43 \\
\hline Astronium sp. & Aroeira & Nativa & 3 & 0,32 \\
\hline Spondias purpurea & Seriguela & Nativa & 3 & 0,32 \\
\hline Jacaranda cuspidifolia & Caroba & Nativa & 3 & 0,32 \\
\hline Tecoma stans & Ipêzinho-de-jardim & Exótica & 3 & 0,32 \\
\hline Albizia hasslerii & Farinha-seca & Nativa & 3 & 0,32 \\
\hline Guazuma ulmifolia & Mutamba & Nativa & 3 & 0,32 \\
\hline Morus nigra & Amora-preta & Exótica & 3 & 0,32 \\
\hline Nectandra sp. & Canela & Nativa & 2 & 0,21 \\
\hline Roystonea oleracea & Palmeira real & Exótica & 2 & 0,21 \\
\hline Tabebuia aurea & Paratudo & Nativa & 2 & 0,21 \\
\hline Cupressus sp. & Cupresso & Exótica & 2 & 0,21 \\
\hline Inga $\mathrm{sp}$. & Ingá & Nativa & 2 & 0,21 \\
\hline Callistemon viminalis & Escova-de-garrafa & Exótica & 2 & 0,21 \\
\hline Grevillea banksii & Grevilha-anã & Exótica & 2 & 0,21 \\
\hline Citrus sinensis & Laranjeira & Exótica & 2 & 0,21 \\
\hline Thevetia thevetiodes & Chapéu-de-napoleão & Exótica & 1 & 0,11 \\
\hline Terminalia argentea & Capitão & Nativa & 1 & 0,11 \\
\hline Combretum leprosum & Carne-de-vaca & Nativa & 1 & 0,11 \\
\hline Sapium haematospermum & Leiteiro-chorão & Nativa & 1 & 0,11 \\
\hline Pterogyne nitens & Amendoim-bravo & Nativa & 1 & 0,11 \\
\hline Erythrina sp. & Eritrina & Nativa & 1 & 0,11 \\
\hline Leucaena leucocephala & Leucena & Exótica & 1 & 0,11 \\
\hline Lonchocarpus muehlbergianus & Timbó & Nativa & 1 & 0,11 \\
\hline Cinnamomum zeylanicum & Canela & Exótica & 1 & 0,11 \\
\hline Punica granatum & Romã & Exótica & 1 & 0,11 \\
\hline Hibiscus rosa-sinensis & Hibisco & Exótica & 1 & 0,11 \\
\hline Eriobotrya japonica & Nespereira & Exótica & 1 & 0,11 \\
\hline Genipa americana & Jenipapo & Nativa & 1 & 0,11 \\
\hline \multirow[t]{2}{*}{ Sapindus saponaria } & Saboneteira & Nativa & 1 & 0,11 \\
\hline & Não identificadas & & 11 & 1,18 \\
\hline Total & & & 931 & 100 \\
\hline
\end{tabular}

Do total de indivíduos relatados, constatou-se a presença de 36 mudas $(3,86 \%)$ de quatro espécies: Licania tomentosa (oiti - 55,6\%), Tabebuia roseoalba (Ridl.) Sand (ipê-branco - 25\%), Murraya exotica L. (murta - 8,3\%) e Mangifera indica L. (mangueira - 2,8\%).

Durante a coleta de dados, não foi possível identificar as árvores conhecidas como "ipês", pois não estavam no período de floração, o que inviabilizou a taxonomia a nível de espécie. Dentre os indivíduos classificados como "não identificados", três eram mudas plantadas pelos próprios moradores, que não souberam identificá-las, e seis estavam completamente sem folhas ou tomados por erva-de-passarinho.

Quanto a sua origem, 50,9\% das espécies encontradas são nativas e 49,1\% são exóticas. Dentre as espécies exóticas, oito são consideradas invasoras, segundo a base de dados do Instituto Hórus de Desenvolvimento e Conservação Ambiental (2016): Eriobotrya japonica (Thunb.) Lindl. (nespereira); Leucaena leucocephala (Lam.) R. de Wit (leucena); Mangifera indica L. (mangueira); Melia azedarach L. (cinamomo); Morus nigra (amoreirapreta); Psidium guajava L. (goiabeira); Syzygium cumini (L.) Skeels (jamelão); e Tecoma stans (L.) Juss. Ex Kunth (ipêzinho-de-jardim).

Pela distribuição das árvores inventariadas em classes diamétricas (Figura 2), verifica-se uma tendência decrescente no número de árvores com DAP maiores, havendo uma maior frequência de indivíduos nas classes 
centrais, o que caracteriza uma distribuição unimodal. Esse tipo de curva indica taxas moderadas de plantio ou reposições, porém com aumento na concentração de árvores em estágios de maturidade, provendo máximos benefícios (BOBROWSKI, 2011).

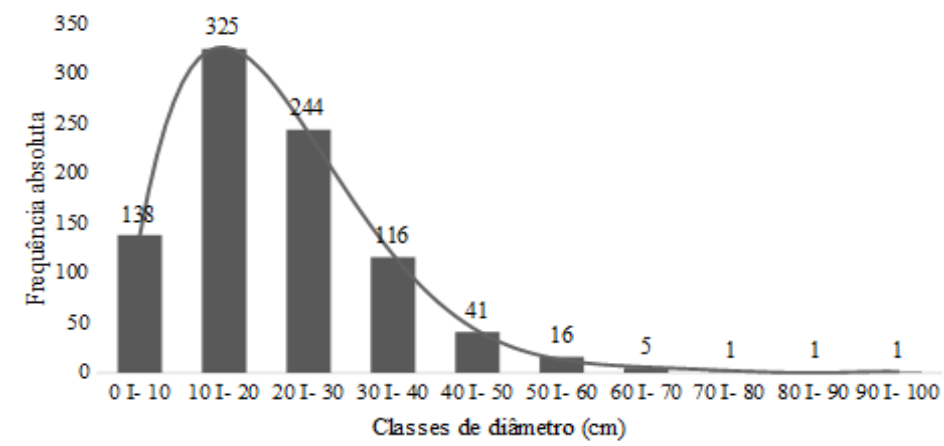

Figura 2. Distribuição diamétrica da arborização viária de Bonito (MS).

Figure 2. Diametric distribution of street trees from Bonito (state of Mato Grosso do Sul, Brazil).

Na Figura 3, pode-se observar a curva da distribuição das árvores em classes de altura, também caracterizada como unimodal. Há maior quantidade de indivíduos $(43,5 \%)$ na segunda classe (de 3 a 6 metros) do que na primeira classe, que possui $19,1 \%$ dos indivíduos.

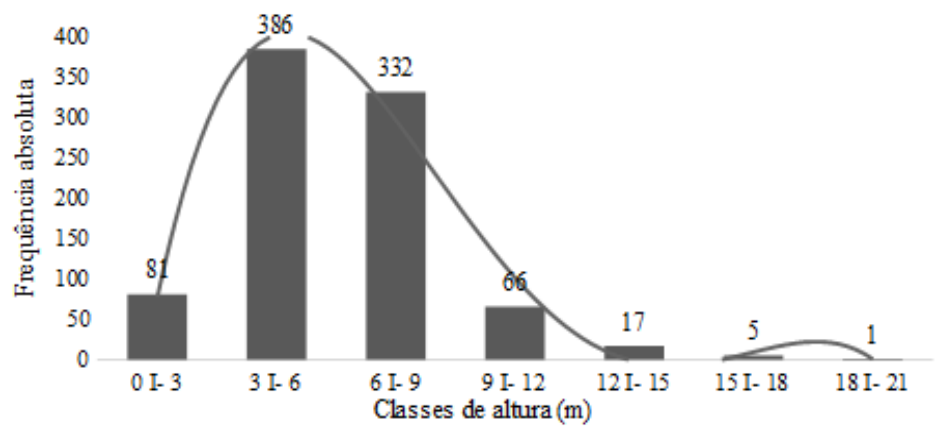

Figura 3. Distribuição hipsométrica da arborização viária de Bonito (MS).

Figure 3. Distribution into height classes of street trees from Bonito (state of Mato Grosso do Sul, Brazil).

Em relação às mudas, a altura média encontrada foi de $1,38 \mathrm{~m}$, o que significa que os novos plantios não atenderam aos critérios técnicos que determinam que uma muda adequada para implantação na rua deve possuir tamanho mínimo de 2,0 m de altura (BIONDI; ALTHAUS, 2005).

Ao contrário das distribuições diamétricas e hipsométricas, a análise da distribuição dos dados em classes de área de copa demonstrou uma tendência decrescente, com curva em forma de "J" invertido (Figura 4).

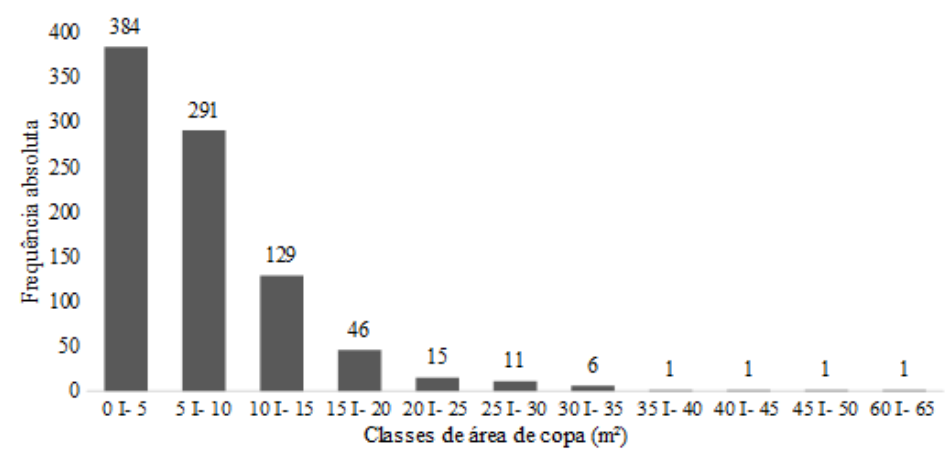

Figura 4. Distribuição em classes de área de copa da arborização viária de Bonito (MS).

Figure 4. Distribution into canopy area classes of street trees from Bonito (state of Mato Grosso do Sul, Brazil).

FLORESTA, Curitiba, PR, v. 48, n. 2, p. 235-244, abr/jun 2018

Zamproni. K. et.al.

ISSN eletrônico 1982-4688

DOI: $10.5380 /$ rf.v48 i 2.55531 
Essa característica é um reflexo das diferentes formas de área de copa inerentes a cada espécie que compõe a arborização viária. Assim como ocorre com a distribuição hipsométrica, a dinâmica da área de copa também é fortemente influenciada pelo tipo e intensidade de poda realizada, que alteram as características típicas de cada espécie, conforme Bobrowski (2011). A altura de bifurcação média dos indivíduos arbóreos amostrados foi de 1,17 metros, sendo que $80 \%$ apresentaram altura da primeira bifurcação inferior a 1,8 m e 4,8\% possuíam bifurcação rente ao solo

Em relação à classificação de condição física e fitossanitária, 52,31\% das árvores foram consideradas regular, com condição fisíca e vigor medianos, demonstrando recuperação satisfatória após sofrerem danos. As árvores classificadas como boas somam $27,39 \%$ do total. Foram classificadas $14,18 \%$ das árvores como ruins, $1,50 \%$ como muito ruins e $0,75 \%$ como árvores mortas.

A Figura 5 apresenta a distribuição dos indivíduos avaliados nas classes de condição física e fitossanitária para as dez espécies mais frequentes em Bonito. Excluíram-se os indivíduos de L. tomentosa já que o predomínio dessa espécie impede a visualização das demais espécies no gráfico por causa da escala.

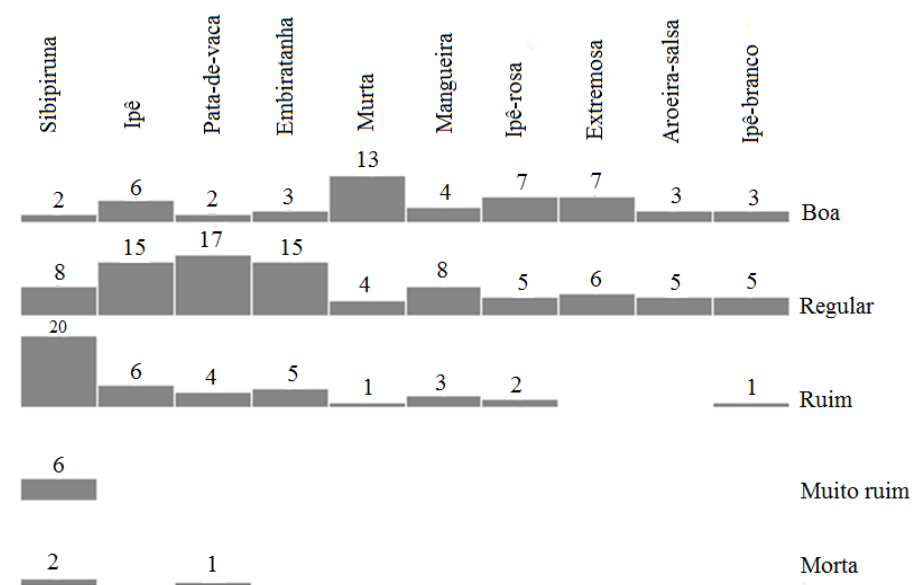

Figura 5. Avaliação da condição física e fitossanitária das dez espécies mais frequentes na arborização viária de Bonito (MS), excluindo-se L. tomentosa.

Figure 5. Assessment of the physical and phytosanitary condition of the ten most frequent species of the street trees of Bonito (state of Mato Grosso do Sul, Brazil), excluding L. tomentosa.

Verifica-se que, proporcionalmente, M. exotica (murta) apresenta mais árvores em condição boa. As espécies Lagerstroemia indica L. (extremosa) e Schinus molle L. (aroeira-salsa) demonstraram condições de desenvolvimento e adaptabilidade satisfatórias no município, com indivíduos classificados somente como bons ou regulares, sendo um indicativo de espécies promissoras para novos plantios. De modo geral, Caesalpinia pluviosa Benth. (sibipiruna) apresenta classificação ruim, comprometendo a qualidade da arborização por ser a segunda espécie mais frequente e necessitando, portanto, de cuidados especiais de manutenção e manejo.

Foram diagnosticadas 22 árvores $(2,36 \%)$ com presença de cupins, 14 (1,5\%) com presença de percevejo, $13(1,39 \%)$ com presença de fungo/ferrugem, nove $(0,97 \%)$ com presença de formigas e cinco $(0,54 \%)$ com presença de erva-de-passarinho. Dentre os indivíduos atacados por cupins, $54,5 \%$ correspondem a C. pluviosa (sibipiruna). Duarte et al. (2008) afirmam que a presença de cupins tem relação com a condição fitossanitária ruim, injúrias mecânicas e idade mais avançada das árvores. Isso representa um bioindicador negativo de qualidade e necessidade de erradicação das árvores, conforme Albertin et al. (2011).

Das 589 árvores inventariadas de L. tomentosa (oiti), foram diagnosticadas nove com presença de percevejo, oito com presença de formiga, uma com ataque de cupim e uma com presença de fungo. Isso indica boa resistência da espécie ao ataque de pragas e doenças mesmo que o plantio da espécie seja caracterizado como uma monocultura na cidade, criando condições favoráveis para a proliferação dos patógenos.

Diversos indivíduos apresentaram danos no fuste e nos galhos decorrentes de podas mal executadas, acidentes com veículos, vandalismo ou devido ao uso para fins medicinais. Em 40 indivíduos (4,3\%), esses danos foram severos, comprometeram a estabilidade da árvore e aumentaram a suscetibilidade a ataque de patógenos (Figura 6). 

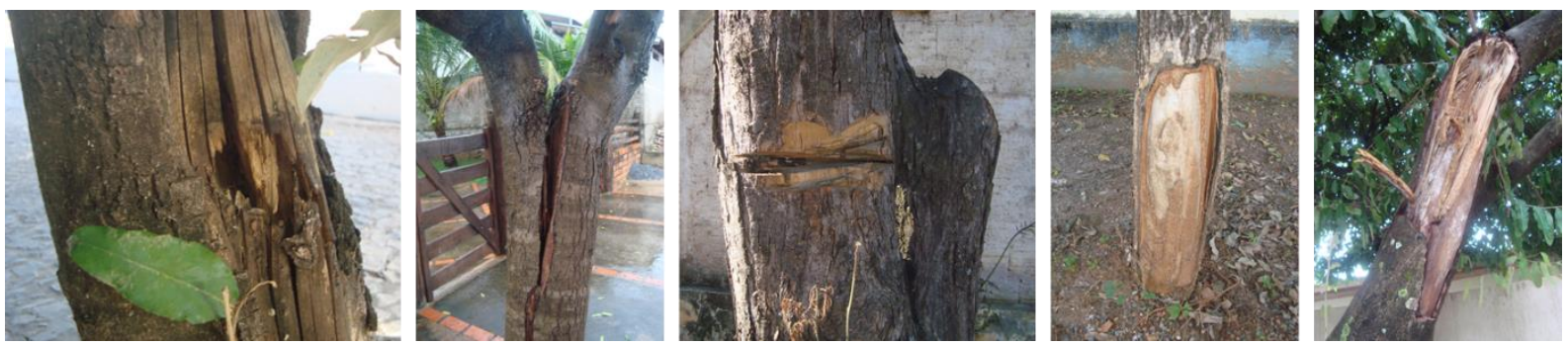

Figura 6. Diversos danos físicos encontrados nas árvores de Bonito (MS)

Figure 6. Physical damages found in trees from Bonito (state of Mato Grosso do Sul, Brazil).

Referente às necessidades de tratamento, recomenda-se que 55 árvores (5,74\%) sejam removidas por estarem mortas, atacadas por cupins, com rachadura no fuste e/ou inseridas em lugares inadequados, causando transtornos e oferecendo riscos para a população. Dentre os indivíduos indicados para esse tipo de intervenção, $43,64 \%$ são C. pluviosa (sibipiruna) e 14,55\% são L. tomentosa (oiti).

Cerca de $44 \%$ das árvores apresentaram algum tipo de conflito ou necessitam de algum tipo de intervenção mediante poda de adequação/direcional para reduzir conflitos com os componentes urbanos (rede de energia e comunicação, construções). A necessidade de podas de levantamento de copa em 15,12\% das árvores está intimamente relacionada à baixa altura de bifurcação encontrada nas árvores, problema proveniente da produção e plantio de mudas de má qualidade, com características inadequadas para a implementação no meio urbano. Essas características podem ser melhoradas com o planejamento e manejo adequado das mudas ainda no viveiro.

Com relação ao sistema radicial, foram classificadas com raiz profunda 70,43\% das árvores, $16,47 \%$ com raiz pouco superficial e 6,86\% com raiz superficial danificando o calçamento. Dessa maneira, a arborização viária de Bonito não apresenta graves problemas de conflito entre o calçamento e as raízes. Dentre os indivíduos que apresentaram raiz superficial, 61,54\% são da espécie L. tomentosa (oiti), 12,31\% são de C. pluviosa (sibipiruna) e 4,62\% são Ficus sp (fícus) e T. roseoalba (ipê-branco) respectivamente.

\section{DISCUSSÃO}

A diversidade de espécies encontrada no levantamento florístico pode ser considerada alta para um município de pequeno porte, quando comparada com valores encontrados em centros urbanos maiores como Assis (SP) com 54 espécies (ROSSATO et al., 2008) e Rio Branco (AC) com 39 espécies (PAIVA et al., 2010).

Observa-se um equilíbrio no uso de espécies nativas e exóticas, porém seria interessante priorizar a utilização de nativas nos novos plantios de modo a valorizar a flora regional que é rica em diversidade e beleza. Referente às espécies exóticas invasoras, Bobrowski e Biondi (2015) afirmam que o problema da presença dessas espécies na arborização viária reside no fato de as sementes poderem ser dispersas para os maciços florestais do entorno, comprometendo sua qualidade e integridade biológica. Especialmente no município de Bonito, que está inserido numa região em que a flora possui funções expressivas no âmbito ambiental, social e econômico, é recomendado que se planeje o manejo dessas espécies de forma adequada.

A frequência encontrada da espécie L. tomentosa (oiti) excede a proposta por Grey e Deneke (1978), que recomendam uma frequência entre 10 e $15 \%$ de uma mesma espécie em zonas urbanas para evitar que a arborização de ruas de uma cidade seja dizimada por um surto de pragas e doenças.

Apesar da preferência por essa espécie na composição da arborização viária poder ser justificada por sua copa densa e perenifólia, que proporciona excelente sombreamento, Ferreira et al. (2001) alertam que o plantio de $L$. tomentosa (oiti) em larga escala deve ser evitado em função do aparecimento de ferrugem, causada por Phakopsora tomentosae, que promove a morte da árvore, conforme encontrado pelos autores em Manaus (AM).

Dessa forma, a homogeneidade da arborização em Bonito é preocupante, pois os indivíduos de oiti podem estar susceptíveis ao ataque de fitopatógenos, que acarretam na morte das árvores e, consequentemente, num déficit expressivo na quantidade de árvores na cidade. Além disso, ruas contendo plantios de uma mesma espécie propiciam uma certa monotonia na paisagem do município.

Com relação ao menor número de indivíduos na primeira classe de diâmetro referente a distribuição unimodal, McPherson et al. (2016) ressaltam a importância de uma elevada proporção de indivíduos na classe de menor diâmetro para compensar a mortalidade relacionada à fase de estabelecimento das mudas. Já quanto à distribuição hipsométrica, Bobrowski (2011) ressalta que a distribuição em classes de altura da arborização sofre influência direta do tipo de poda realizada, principalmente por podas drásticas, em que toda ou a maioria da copa

FLORESTA, Curitiba, PR, v. 48, n. 2, p. 235-244, abr/jun 2018

Zamproni. K. et.al.

ISSN eletrônico 1982-4688

DOI: $10.5380 /$ rf.v48 i2.55531 
foi retirada, e de rebaixamento de copa, as quais alteram as características naturais de altura e arquitetura de copa das espécies, prática que se verificou ser bastante comum em Bonito, conforme exemplifica a Figura 7.
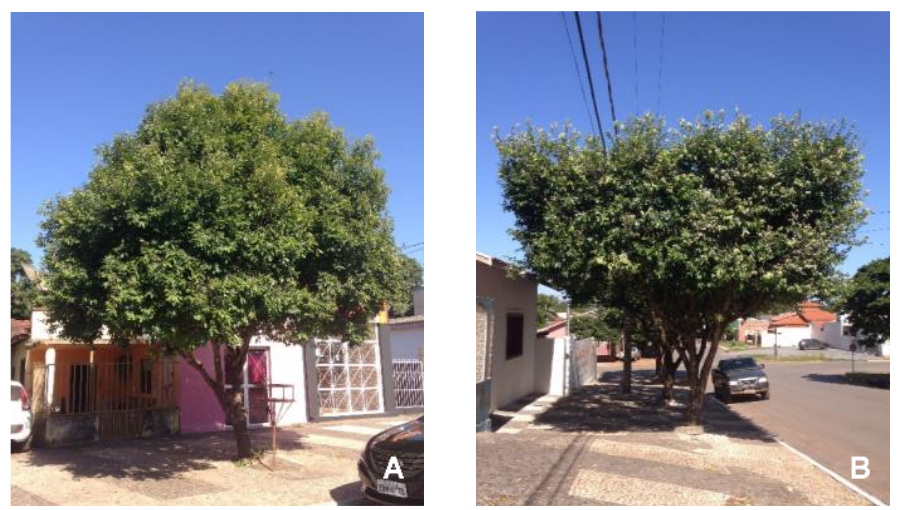

Figura 7. Indivíduos de L. tomentosa sem poda (A) e com poda (B) de rebaixamento de copa em Bonito (MS). Figure 7. Trees of L.tomentosa with no pruning (A) and with topping (B) in Bonito (state of Mato Grosso do Sul, Brazil).

Em uma cidade com altas temperaturas ao longo de todo o ano como Bonito, é importante que haja um adequado sombreamento proporcionado pela arborização para mitigar o desconforto térmico causado pelo calor. No entanto, observa-se um predomínio de copas pequenas, seja pelo porte e idade das árvores ou pelo tipo de poda realizada. Sendo assim, não cumprem adequadamente a função ambiental desejada para árvores nas calçadas. A cobertura de copa e o porte são características diretamente relacionadas ao efeito de frescor proporcionado pelas árvores no meio urbano (MULLANEY et al., 2015).

Ainda nesse sentido, Biondi e Althaus (2005) afirmam que, em locais de clima quente, é recomendável árvores de copa densa e que não percam as folhas durante o inverno em função da sombra que proporcionam. Assim, C. pluviosa (sibipiruna), segunda espécie mais frequente em Bonito, não é a mais aconselhável para a arborização de ruas do município, pois é caducifólia.

Recomenda-se que a altura da primeira bifurcação (ponto de inserção do primeiro galho no tronco) não seja menor que 1,8 metros, pois representa um problema com relação ao trânsito livre dos pedestres, principalmente para aqueles com mobilidade reduzida (LIMA NETO et al., 2010). A predominância de árvores com altura de bifurcação inferior ao recomendado em Bonito é um reflexo da baixa qualidade das mudas utilizadas na arborização viária e um indicativo de que o plantio tem sido realizado pelos próprios moradores, que desconhecem as normas técnicas.

Quanto aos danos físicos encontrados na arborização viária do município, Paiva et al. (2010) advertem que o manejo inadequado das árvores de rua, principalmente no que se refere às podas mal executadas, compromete a estabilidade, fitossanidade e vigor dos indivíduos podendo até mesmo ocasionar suas mortes.

Biondi e Althaus (2005) afirmam que a poda é uma prática de manutenção muito importante para árvores de rua e deve ser executada por pessoas habilitadas para não afetar a saúde e a estética das árvores. Martins et al. (2010) explicam que, quando uma poda é conduzida inadvertidamente, sem uso de técnicas específicas, a árvore é prejudicada pela alteração na arquitetura de sua copa e exposição do lenho à entrada de patógenos.

A Lei complementar $n^{\circ}$ 36/2000, que dispõe sobre o Código de Posturas do Município de Bonito, estabelece que o corte e a poda de árvores são de competência exclusiva do poder público municipal (BONITO, 2000). Todavia, essa determinação é notadamente violada pelos moradores da cidade, conforme verificado em campo. Como consequência disso, as árvores estão sofrendo danos físicos e estéticos.

De acordo com Zem e Biondi (2014), mesmo com os inúmeros benefícios proporcionados pelas árvores de ruas, estas continuam sendo danificadas devido à falta de planejamento quanto ao local onde serão plantadas e à falta de envolvimento da população, que deveria ser considerado uma prioridade em todas as fases da arborização de uma cidade. Segundo Paiva et al. (2010), as medidas recomendadas para reverter essa tendência de depreciação das árvores urbanas seriam a adoção de um programa de educação ambiental junto à comunidade local, enfatizando os benefícios proporcionados pela arborização ao meio urbano, implementação de normas legais para o manejo das árvores e ministração de cursos de poda para todos os agentes envolvidos nessa prática no município. 


\section{CONCLUSÕES}

Através deste estudo, foi possível encontrar:

- Uma homogeneização da arborização viária do município de Bonito (MS), com a predominância de Licania tomentosa (oiti). Embora a espécie esteja bem adaptada às condições locais, sugere-se a adoção de medidas de introdução de novas espécies a fim de diminuir a frequência de oitis, bem como a suspensão de novos plantios dessa espécie, de modo a contribuir para a melhoria estética e ecológica da cidade.

- Espécies promissoras que podem ser incrementadas em novos plantios de modo a alterar a proporção de oiti são: Lagerstroemia indica (extremosa); Schinus molle (aroeira-salsa); Handroanthus ochraceus (ipêamarelo); e Tabebuia roseoalba (ipê-branco).

- Não é recomendado o uso futuro de Caesalpinia pluviosa (sibipiruna), pois apresentou susceptibilidade a ataque de cupins.

- A altura de bifurcação encontrada nos indivíduos inventariados é problemática, pois a grande maioria está abaixo dos padrões técnicos, que recomendam altura mínima de $1,8 \mathrm{~m}$. Sugere-se a adoção de podas de levantamento de copa para as árvores já implantadas nas ruas. Para os novos plantios, sugere-se estabelecer um padrão de qualidade das mudas referente à altura e diâmetro.

- Não foram detectados problemas significativos com relação a pragas e doenças, porém foram observados vários danos físicos. Dessa maneira, recomenda-se a adoção de programas de educação ambiental no município para maior conscientização da população a respeito da importância das árvores no meio urbano.

- Em relação às podas, recomenda-se o treinamento de profissionais para sua realização, de forma que sejam executadas adequadamente e atendam às reais necessidades das árvores em conjunto com a fiscalização desta atividade por parte do poder público.

\section{AGRADECIMENTOS}

À Fundação Neotrópica do Brasil e à Prefeitura Municipal de Bonito (MS) pela oportunidade de realização deste trabalho e apoio financeiro.

\section{REFERÊNCIAS}

ALBERTIN, R. M.; DE ANGELIS, R.; DE ANGELIS NETO, G.; DE ANGELIS, B. L. D. Diagnóstico qualiquantitativo da arborização viária de Nova Esperança, Paraná, Brasil. RevSBAU, Piracicaba, v.6, n.3, p.128-148, 2011.

BAUR, J. W. R.; TYNON, J. F.; RIES, P.; ROSENBERGER, R. S. Public attitudes about urban forest ecosystem services management: A case study in Oregon cities. Urban Forestry \& Urban Greening, Davis, v.17, n.1, p.4253, 2016.

BENATTI, D. P.; TONELLO, K. C.; ADRIANO JÚNIOR, F. C.; SILVA, J. M. S.; OLIVEIRA, I. R.; ROLIM, E. N.; FERRAZ, D. L. Inventário arbóreo urbano do município de Salto de Pirapora, SP. Revista Árvore, Viçosa, v.36, n.5, p.887-894, 2012.

BIONDI, D.; ALTHAUS, M. Árvores de rua de Curitiba: cultivo e manejo. Curitiba: FUPEF, 2005, 182 p.

BOBROWSKI, R. Inventário florestal contínuo e dinâmica da arborização de ruas. In: BIONDI, D.; LIMA NETO, E. M. Pesquisa em arborização de ruas. Curitiba: O Autor, 2011, 150 p.

BOBROWSKI, R.; BIONDI, D. Influência das espécies exóticas invasoras na expressão da diversidade da arborização de ruas de Curitiba-PR. RevSBAU, Piracicaba, v.10, n.2, p.27-39, 2015.

BONITO. Lei complementar $\mathbf{n}^{\mathbf{0} 36}$, de 12 de dezembro de 2000. Dispõe sobre o Código de Posturas do Município de Bonito-MS e dá outras providências. Disponível em: < goo.gl/mVXmQx >. Acesso em 28 nov. 2016.

DUARTE, F. G.; SANTOS, G. A.; ROSADO, F. R.; DELARIVA, R. L.; SAMPAIO, A. C. F. Cupins (Insecta: Isoptera) na arborização urbana da zona 1 de Maringá-PR. Revista em Agronegócios e Meio Ambiente, Maringá, v. 1, n. 1, p. 87-99, 2008.

FLORESTA, Curitiba, PR, v. 48, n. 2, p. 235-244, abr/jun 2018

Zamproni. K. et.al.

ISSN eletrônico 1982-4688 
FEHLAUER, T. J.; RODRIGUER-OTUBO, B. M.; SANDRINI, M.; DESTRO, D. Caracterização da produção de genótipos de banana introduzidos na região de Bonito - MS. Revista Brasileira de Fruticultura, Cruz das Almas, v. 32, p. 938-943, 2010.

FERREIRA, F. A.; GASPAROTTO, L.; LIMA, M. I. P. M. Uma ferrugem, causada por Phakopsora tomentosae em oiti, em Manaus. Fitopatologia Brasileira, Brasília, v.26, n.2, p. 206 - 208, 2001.

GREY, G. W.; DENEKE, F. J. Urban forestry. New York: John Wiley, 1978.

INSTITUTO BRASILEIRO DE GEOGRAFIA E ESTATÍTICA (IBGE). Estimativa da população. 2016. Disponível em: <goo.gl/YVoJOF>. Acesso em: 27 out. 2016.

INSTITUTO BRASILEIRO DE GEOGRAFIA E ESTATÍTICA (IBGE). Informações municipais. 2010. Disponível em: <goo.gl/b1Rvmx>. Acesso em: 27 out 2016.

INSTITUTO HÓRUS DE DESENVOLVIMENTO E CONSERVAÇÃO AMBIENTAL. Base de dados nacional de espécies exóticas invasoras I3N Brasil. 2016. Disponível em: 〈http://i3n.institutohorus.org.br/www〉. Acesso em: 28 nov. 2016.

KORDY, A. E.; SOBH, H.; MOSTAFA, A. The Problem of Applying Sustainability Ideas in Urban Landscape in Developing Countries. Procedia Environmental Sciences, v. 34, p.36-48, 2016.

LIMA NETO, E. M.; BARDELLI-DA-SILVA, M. Y.; SILVA, A. R.; BIONDI, D. Arborização de ruas e acessibilidade no bairro centro de Curitiba-PR. RevSBAU, Piracicaba, v.5, n.4, p.40-56, 2010.

MARTINS, L. F. V.; ANDRADE, H. H. B.; DE ANGELIS, B. L. D. Relação entre podas e aspectos fitossanitários em árvores urbanas na cidade de Luiziana, Paraná. RevSBAU, Piracicaba, v.5, n.4, p.141-155, 2010.

MCPHERSON, E. G., VAN DOORN, N., GOEDE, J. Structure, function and value of street trees in California, USA. Urban Forestry \& Urban Greening, Davis, v. 17, p.104-115, 2016.

MULLANEY, J.; LUCKE, T.; TRUEMAN, S.J. A review of benefits and challenges in growing street trees in paved urban environments. Landscape and Urban Planning, Amsterdam, v.134, p.157-166, 2015.

NOWAK, D. J. Assessing urban forest structure: summary and conclusions. Arboriculture \& Urban Forestry, Champaing, v.34, n.6, p.391-392, 2008.

OliVEIRA, L. M.; SANTOS, A. F.; SOUZA, P. A.; ALVES, K.C. C. L. F.; GIONDO, M. Diagnóstico da arborização nas calçadas de Gurupi, TO. RevSBAU, Piracicaba, v.12, n.1, p.105-121, 2017.

PAIVA, A. V.; LIMA, A. B. M.; CARVAlHO, A.; JUNIOR, A.; GOMES, A.; MELO, C. S.; FARIAS, C. O.; REIS, C.; BEZERRA, C.; JUNIOR, E. A. S.; MACEDO, E.; LIMA, E. S.; SOBRINHO, F.; SILVA, F. M.; BONFIM, J. C.; JUNIOR, L. S.; CORREA, M.; DUMONT, M. L.; JUNIOR, M. A. I.; PANTOJA, N. V.; DAVILA, R. M.; GABRIEL, R.; SILVA, R. A.; CUNHA, R. M.; OLIVEIRA, R. S.; DIAS R.; NICHELI, S. P.; COSTA, S.; SOUZA, T. C.; PEREIRA, T. F.; CASTELO, Z.; FERRARI, Z. S. Inventário e diagnóstico da arborização urbana viária de Rio Branco, AC. RevSBAU, Piracicaba, v.5, n.1, p.144-159, 2010.

RIBEIRO, F.A.B.S. Arborização urbana em Uberlândia: percepção da população. Revista da Católica, Uberlândia, v.1, n.1, p. 224-237, 2009.

ROSSATO, D. R.; TSUBOY, M. S. F.; FREI, F. Arborização urbana na cidade de Assis-SP: uma abordagem quantitativa. RevSBAU, Piracicaba -, v. 3, n. 3, p. 1-16. 2008.

SILVA, M. B.; ANJOS, L. H. C.; PEREIRA, M. G.; SCHIAVO, J. A.; COOPER, M.; CAVASSANI, R. S. Gênese e classificação dos solos de uma topossequência em área de carste na Serra da Bodoquena, MS. Revista Brasileira de Ciência do Solo, Viçosa-, v. 31, n. 6, 2013.

ZEM L. M.; BIONDI, D. Análise da percepção da população em relação ao vandalismo na arborização viária de Curitiba - PR. RevSBAU, Piracicaba, v.9, n.3, p.86-107, 2014. 